\title{
THE IMPACT OF MODIFYING OCCUPATIONAL RISK FACTORS ON THE OUTCOME OF TREATMENT OF CHRONIC VENOUS ULCER.
}

\author{
By \\ Refaat T. M.*, Ewis A. A.*, Osman A. O.**, El-Sanadiki M. N. ** \\ *Departments of Occupational Medicine and **Vascular Surgery, \\ Faculty of Medicine, Minia University, Minia, Egypt.
}

\begin{abstract}
:
Venous hypertension and chronic venous disease (CVD) occur frequently in the working population. Several epidemiological studies have shown statistically significant association between CVD and duration of standing and sitting at work. This study evaluates the impact of modifying and correcting different occupational risk factors on the outcome of treatment of chronic venous ulcer.

Patients were divided into 2 groups: group A (17 patients) were subjected to combined conservative treatment followed by surgical treatment and group B (15 patients) were treated only by surgical treatment. The conservative treatment consisted of educational sessions on occupational risk factors and compression therapy.

The results showed similar figures of demographics, risk factors, clinical characteristics and current occupation in the studied groups. In group A, all patients healed; (2/17) showed short term healing and (15/17) showed long term healing. While in group B (3/15) patients showed no healing, (5/15) showed short term healing and (7/15) showed long term healing. The differences being statistically significant $\left(X^{2}=7.1, P=0.02\right)$

This indicates that for treatment of indolent chronic venous ulceration modifying occupational risk factors and adverse lifestyle behaviors will have a significant impact on the results of treatment.
\end{abstract}

Key words: chronic venous ulcer, occupational risk factors, conservative treatment, surgical treatment. 


\section{Introduction:}

Chronic venous insufficiency and leg ulcers affect approximately 1-2 per 1000 of normal population. Healing rates of venous ulcer can be poor, with up to $50 \%$ remaining open and unhealed for as long as 9 months. Ulcer recurrence rates are worrying with up to one third of treated patients on their fourth or more episodes (Palfreyman et al., 2007).

In 1994, the American Venous Forum (Eklof et al., 2004) defined standards in the CEAP classification scheme which is based on the clinical classification of the disease and on etiological, anatomical and pathophysiological factors as shown in table I.
Venous hypertension and chronic venous disease occur frequently in working population. Several epidemiological studies have shown statistically significant association between CVD and duration of standing and sitting at work (Tuchsen et al., 2000).

This study evaluates the impact of modifying and correcting different risk factors with special emphasis on occupational background. The study population was selected from those presented to the surgical outpatient clinic in two major hospitals, Minia University Hospital and Minia General Hospital over a 48 months period (July 2009 - June 2011). The main complaint was severe chronic venous disease (CVD) corresponding with $\mathrm{C} 4, \mathrm{C} 5$ and $\mathrm{C} 6$ in the CEAP Classification of CVD. 
Table (I): Clinical, etiological, anatomical, and pathophysiological (CEAP) classification of chronic venous disease.

\begin{tabular}{|c|c|}
\hline \multicolumn{2}{|l|}{ Clinical } \\
\hline Class $0 \ll \mathrm{C} 0 »$ & No visible or palpable signs of venous disease \\
\hline Class $1 \ll \mathrm{C} 1 »$ & Telangioectasia or reticular veins \\
\hline Class $2 \ll \mathrm{C} 2 »$ & Varicose veins \\
\hline Class $3 \ll \mathrm{C} 3 »$ & Edema \\
\hline Class $4 \ll \mathrm{C} 4 »$ & Skin changes (lipodermatosclerosis, atrophe blanche ) \\
\hline Class $5 \ll \mathrm{C} 5 »$ & Healed ulceration \\
\hline Class $6 \ll \mathrm{C} 6 »$ & Active ulceration \\
\hline \multicolumn{2}{|l|}{ Etiological } \\
\hline Etiological Congenital «Ec» & Congenital (may be present at birth or recognized later ) \\
\hline Etiological Primary «Ep» & Primary \\
\hline Etiological Secondary «Es» & Secondary (post-traumatic, post-thrombotic) \\
\hline \multicolumn{2}{|l|}{ Anatomical } \\
\hline Anatomical Superficial «As» & Superficial veins (numbered 1 to 5 ) \\
\hline Anatomical Deep «Ad» & Deep veins (numbered 6 to 16 ) \\
\hline Anatomical Perforating «Ap» & Perforating veins (numbered 17 and 18 ) \\
\hline \multicolumn{2}{|l|}{ Pathophysiological } \\
\hline Pathophysiological Reflux «Pr» & Reflux \\
\hline Pathophysiological Obstruction «Po» & Obstruction \\
\hline Pathophysiological Both «Pr,o» & Both \\
\hline
\end{tabular}

Quated from Andrew W.B. and Peter J.P., J. Vasc. Surg. 1999, (Andrew and Peter, 1999) 


\section{Patients and methods:}

\section{Inclusion Criteria:}

- Patients with evident CVD (C4, $\mathrm{C} 5$ and C6) with varicose veins, post -thrombotic limb, incompetent perforators or valvular incompetence for more than 3 months were included.

- $\quad$ Patients whose ages ranged between 18 and 60 years.

- Patients and control were all currently, employed.

- Patients with chronic venous ulceration.

\section{Exclusion criteria:}

- Patients with very recent small superficial ulcerations or those uncooperative patients who fails to cope with regular follow up.

- Patients with peripheral arterial disease (defined by $\mathrm{ABI}<0.9$ )

- History of any systemic disease.

- History of any debilitating disease.

All the 32 patients who fulfilled the inclusion criteria were recruited and subjected to careful history taking with special emphasis and stress on occupational history and whether he was employed in a skilled or unskilled occupation.
Questions about immobility and bowel activity were asked, history of hernia surgery, diverticulosis, diverticulitis, and non-lower limb abnormalities were assessed. Women were asked about their reproductive history.

Patients were classified as one of three categories; prolonged sitting, prolonged standing or actively moving according to their usual daily activities.

Family history of varicose veins in the first degree relatives, past history of previous similar conditions, previous deep venous thrombosis was also, inquired about.

At the study visits trained interviewers followed standardized protocol to obtain information on demographics, lifestyle and personal, family and medical history.

The subject's current occupation was classified by the interviewers as "professional", "technical, administrative, managerial", "clerical skilled, semi skilled or laborer ".

Proper clinical examination of the ulcer gives a good idea about the underlying condition whether varicose vein or postthrombotic limb. It also indicates the presence of the incompetent perforators and it characterizes the ulcer and the ulcer 
bearing area as regard size, tenderness, induration and the condition of the surrounding skin.

All patients underwent proper general and local clinical examination; skin trophic changes of the gutter area of the lower leg, such as pigmentation (pigmented dermatitis ); dermatitis (venous eczema ); induration (lipodermatosclerosis); white atrophy, ulcer scars (healed ulcers) and active ulcers, the presence of pitting edema in the pre-tibial or malleolar area were also noted. Proper laboratory investigations and duplex scan for the venous system of the lower limb were done.

Laboratory investigations included blood picture for detection of anemia, leucocytic count and platelet counts; blood glucose level; lipid profile; blood urea; serum albumin and creatinine; and culture and sensitivity testing for any infected ulcer.

Duplex scan to assess venous patency and valvular incompetence in both deep and superficial venous system was also carried out.
The surgical treatment included sapheno-femoral disconnection (Trendlenberg operation), ablation of blow outs at sites of incompetence and subfascial ligation (Cokett and Dudd operation).

In our interventional-trial study, 32 Patients who fulfilled the inclusion criteria were recruited and then randomly divided into 2 groups; group A (17 patients) were subjected to combined conservative treatment and later on surgical treatment and group B (15 patients) were treated only by surgical treatment.

The conservative treatment consisted of educational sessions to inform these patients about the risk factors that aggrevate their severe venous disease, and a protocol of measures that they should follow to avoid and modify and correct the risk factors e.g., avoidance of prolonged sitting or standing, bed rest, leg elevation, compression therapy, etc.

The surgical treatment consisted of open subfascial ligation with or without superficial vein surgery and peri-ulcer ligation of varicose veins. 


\section{Results:}

Table (II): Demographic data and risk factors in patients with severe chronic venous disease of both studied groups.

\begin{tabular}{|l|c|c|}
\hline Variable & $\begin{array}{c}\text { Group A } \\
\text { N=17 }\end{array}$ & $\begin{array}{c}\text { Group B } \\
\text { N=15 }\end{array}$ \\
\hline Sex & M=7 F=10 & M=6 F=9 \\
\hline Age (years) & $39.7 \pm 6.3$ & $45.2 \pm 8.2$ \\
\hline Mean Height (cm) & $168.3 \pm 5.1$ & $172.3 \pm 3.5$ \\
\hline Mean Weight (kg) \pm SD & $79.5 \pm 5.5$ & $81.8 \pm 4.8$ \\
\hline BMI (kgm/m²) & $27.1 \pm 2.7$ & $29.5 \pm 1.1$ \\
\hline $\begin{array}{l}\text { Smoking index (for the males only «all the included males } \\
\text { were smokers») }\end{array}$ & 400 & 475 \\
\hline Blood Pressure (mmHg) & $130 / 85$ & $125 / 90$ \\
\hline History of CVD (\%) & 22 & 21 \\
\hline Hernia surgery in (\%) & 6 & 7 \\
\hline Flat feet in (\%) & 8 & 9 \\
\hline Family history of CVD in (\%) & 22 & 24 \\
\hline Mean duration of professional activity & 5 & 8.2 yrs \pm 0.5 \\
\hline History of DVT in (\%) & 5.3 & 5 \\
\hline Oral contraceptive therapy in females (\%) & 6.3 \\
\hline Obesity (\%) & 5 & 4 \\
\hline
\end{tabular}


Table (III) Clinical data and characteristics of severe chronic venous disease patients of both the studied groups.

\begin{tabular}{|c|c|c|c|c|}
\hline \multirow{2}{*}{\multicolumn{2}{|c|}{ Sex }} & Group A & Group B & \\
\hline & & $\mathrm{M}=7 \quad \mathrm{~F}=10$ & $\mathrm{M}=6 \quad \mathrm{~F}=9$ & \\
\hline \multicolumn{2}{|l|}{ Age (years) } & $39.7 \pm 6.3$ & $43.2 \pm 8.2$ & \\
\hline \multicolumn{2}{|l|}{ Height $(\mathrm{cm})$} & 168.3 & 172.3 & \\
\hline \multicolumn{2}{|c|}{$\mathrm{BMI}\left(\mathrm{kgm} / \mathrm{m}^{2}\right)$} & 27.1 & 32.5 & \\
\hline \multicolumn{2}{|c|}{ Superf. veins disease } & 3 & 2 & \\
\hline \multicolumn{2}{|c|}{ Superf. and perforators veins disease } & 8 & 7 & \\
\hline \multicolumn{2}{|c|}{ Deep and superf. veins disease } & 6 & 6 & \\
\hline \multirow{3}{*}{$\begin{array}{c}\text { Current } \\
\text { occupation }\end{array}$} & Professional & 2 & 2 & \multirow{3}{*}{$\begin{aligned} \mathrm{X}^{2} & =0.0 \\
\mathrm{P} & =0.98\end{aligned}$} \\
\hline & Clerical & 6 & 5 & \\
\hline & Laborer & 9 & 8 & \\
\hline \multicolumn{2}{|c|}{ Current walking (hrs) / day } & 1.0 & 0.9 & \\
\hline \multicolumn{2}{|c|}{ Current standing (hrs) / day } & 4.5 & 4.8 & \\
\hline \multicolumn{2}{|c|}{ Current sitting (hrs) / day } & 5.5 & 6.0 & \\
\hline
\end{tabular}


Table (VI): Treatment results of severe chronic venous disease patients from both groups.

\begin{tabular}{|c|c|c|c|}
\hline & $\begin{array}{c}\text { Group A } \\
\mathrm{n}=17\end{array}$ & $\begin{array}{c}\text { Group B } \\
n=15\end{array}$ & \multirow{6}{*}{$\begin{array}{l}\text { Not Sig } \\
\\
\qquad \begin{array}{r}X^{2}=0.9 \\
P=0.66\end{array}\end{array}$} \\
\hline $\begin{array}{l}\text { Affected leg } \\
\qquad \begin{array}{l}\text { Left leg } \\
\text { Right leg }\end{array}\end{array}$ & $\begin{array}{l}9 \\
8\end{array}$ & $\begin{array}{l}8 \\
7\end{array}$ & \\
\hline $\begin{array}{l}\text { Venous ulcer: } \\
\text { Size }(\mathrm{cm}) \text { small } \\
\text { Large }\end{array}$ & $\begin{array}{l}3 \mathrm{~cm} \\
9 \mathrm{~cm}\end{array}$ & $\begin{array}{l}2 \mathrm{~cm} \\
8 \mathrm{~cm}\end{array}$ & \\
\hline $\begin{array}{l}\text { Cause } \\
\text { Post thrombotic } \\
\text { Varicose veins }\end{array}$ & $\begin{array}{c}10 \\
7\end{array}$ & $\begin{array}{l}9 \\
6\end{array}$ & \\
\hline Duration of treatment (month) & $6.1 \pm 3.6$ & $2 \pm 1.4$ & \\
\hline $\begin{array}{l}\text { Type of surgery (in \%): } \\
-\quad \text { Stripping \& Trendlenberg's op } \\
-\quad \text { Stripping \& Trendlenberg's + } \\
\text { subfascial ligation } \\
-\quad \text { Subfascial ligation only } \\
-\quad \text { Skin graft and / or flap }\end{array}$ & $\begin{array}{l}3 \\
7 \\
7 \\
0\end{array}$ & $\begin{array}{l}2 \\
5 \\
5 \\
3\end{array}$ & \\
\hline $\begin{array}{l}\text { Healing } \\
\text { No healing } \\
\text { Short term healing } \\
\text { Long term healing }\end{array}$ & $\begin{array}{l}0.0 \\
2.0 \\
15.0\end{array}$ & $\begin{array}{l}3.0 \\
5.0 \\
7.0\end{array}$ & $\begin{array}{l}\mathrm{X}^{2}=7.1 \\
\mathrm{P}=0.02 \\
\text { (Significant) }\end{array}$ \\
\hline Recurrence & 2.0 & 5.0 & \\
\hline
\end{tabular}




\section{Discussion:}

Regarding clinical severity of chronic venous disease (CVD), the most consistently correlated risk factors are the presence of varicose veins (Beebe-Dimmer et al., 2005) and deep venous reflux, advanced age, heredity, sedentary lifestyle, increased weight and occupationallyrelated prolonged sitting and standing at work (Carpentier et al., 2004).

Increased CVD severity is also correlated with participant's age. This is expected as increased age is a risk factor for the development of CVD clinical changes, the more severe clinical groups containing predominantly men (Criqui, 2007).

This finding was kept in agreement with the epidemiologic findings of Carpentier et al. (2004) who found an increased prevalence of venous skin changes in men compared with women.

The results of this study showed a significant correlation between severe CVD and the percentage of time standing and percentage of time sitting but no significant correlation with regular walking.

Our study found a good correlation between CVD severity scores and BMI, indicating a positive association between obesity and CVD severity.
Our findings are similar to those of previous reports (Refaat et al., 2006 and Amsler and Blattler, 2007), as patients with increased CVD severity spent more time sitting and less time standing throughout the day compared with other patients. Also patients in clinical classes $\mathrm{C} 4$ to $\mathrm{C} 6$ spent a significant longer proportion of their day standing compared with the control group (Deborah et al., 2004).

The percentage time spent sitting increased with increasing clinical severity of CVD, the patients with clinical severities $\mathrm{C} 4$ to $\mathrm{C} 6$ spent a significantly greater proportion of their day sitting compared with the other groups (Krijnen et al., 1997 and Jungbeck et al., 2002).

Several authors have reported an association between prolonged sitting and standing during work and the development of CVD skin changes. This is thought to be due to prolonged periods of venous hypertension while sitting or standing for prolonged times (Jungbeck et al., 2002). The drawbacks of these studies are that they are subjective and didn't take into account their activities throughout the day i.e. whether or not they perform activities requiring prolonged standing or sitting before and after work (Krijnen et al., 1997). They also failed to take into account 
patient's ambulatory activities, which must play an important role in the development of CVD because it is the loss of venous reflux that results in prolonged elevated venous pressures and consequently in venous skin changes (Stanley et al., 2006).

Researchers demonstrated that patients with healed and active venous ulcers (C4-C6) needed to walk continuously to accomplish the same fall in venous pressure attained by controls after taking a few steps (Stanley et al., 2006). The main cause of chronic venous leg ulcers is venous hypertension which is also known as chronic venous insufficiency that occurs mainly due to deep venous thrombosis or valve incompetence disease. However, further studies done by Barwell and his colleagues (2000) proved that causes of venous ulcer include varicose veins, valvular incompetence and deep venous abnormalities (Barwell et al., 2000).

Besides health education for occupational risk exposure to CVD with informing about the proper positioning and exercise, the conservative treatment included compression therapy, leg elevation and daily dressings of the ulcer. The elastic bandage was preferred more than the elastic stocking as it allows controlling the degree of compression which is variable during this stage; also it allows easier application and more durability especially with repeated application and removal with the dressing and wound care.

The results showed similar figures of demographic and risk factors with no statistically significant difference. Also the data of clinical characteristics, current occupations and affection of different venous systems of the lower extremities showed similar incidence in both groups.

However, modifying the characters of lifestyle and risk factors had a significant impact on the results of healing of venous ulcers.

Our results showed that while all cases of group A healed, there have been 3 cases that did not heal in group B.

Similarly short term healing was observed in five cases of group B while it was evident only in two cases of group A.

However, the main difference was evident in the long term healing of the ulcers, where 15 cases showed good long term healing in group A compared to only 5 cases of group B.

Our results are confirmatory to that of Sybrundy 2001, who found that nearly $60 \%$ of cases healed with long term healing and $40 \%$ with short term healing. 
We can conclude that for these types of indolent chronic ulceration the conservative measures and modifying all the risk factors and the adverse lifestyle behaviors will have a significant impact on the results of treating such cases.

It is worthwhile to give the CVD patient a chance of modifying their different occupational factors and other risk factors in order to magnify the chances for long term healing with no chances for recurrence.

\section{References:}

1. Amsler.F and Blattler W. Compression therapy for occupational leg symptoms and chronic venous disorders- a meta-analysis of randomized controlled trials (2007 European society for vascular surgery).

2. Andrew WB and Peter JP :Chronic Venous Insufficiency. J Vasc Surg 1999; 9:589-92.

3. Barwell JR, Taylor M, and Deacon J. Surgical correction of isolated superficial venous reflux. Long -term recurrence rate in chronic venous leg ulcer. Eur J vasc Endovasc Surg 2000; 20:363-8.

4. Beebe-Dimmer JL, Pfeifer JR, Engle JS, and Schottenfeld D. The epidemiology of chronic venous insufficiency and varicose veins. Ann Epidemiol 2005; 15:175-84.

5. Bergan JJ. Chronic venous disease. N Engl J Med 2006; 355:488-98.

6. Carpentier PH, Maricq HR, Biro C, PoncotMakinen CO, and Franco A. Prevalence, risk factors, and clinical patterns of chronic venous disorders of lower limbs: a population-based study in France. J Vasc Surg 2004; 40:650-9.
7. Criqui MH. Risk factors for chronic venous disease: The San Diego population study. J Vasc Surg 2007; 46: 331-37.

8. Deborah A, Francis P, and Charles N. Management of venous leg ulcer. BMJ. 2004; 328:1358-62.

9. Eklof B, Rutherford RB, Bergan JJ, Carpentier $\mathrm{PH}$, and Gloviezki P. American Venous Forum International Ad Hoc Committee for revision of the CEAP Classification. Revision of the CEAP classification for chronic venous disorders: consensus statement. J Vasc Surg 2004; 40:1248-52.

10. Jungbeck C, Peterson K, Danielsson G, and Norgen L. Effect of compression hosiery in female workers with a standing profession. Phlebology 2002; 16:117-20.

11. Krijnen RM, de Boer EM, Ader HJ, Osinga DS, and Bruynzeel DP. Compression stockings and rubber floor mats: do they benefit workers with chromic venous insufficiency and a standing profession? J Occup Environ Med 1997; 39:889-94.

12. Palfreyman S, Nelson EA and Michaels JA. Dressing for venous leg ulcers: systematic review and meta-analysis. BMJ 2007; 335: 244.

13. Refaat TM, Ewis AA, El Sanadiki MN. Working conditions as risk factors for lower extremity venous disorders among hospital employees. Egyptian J Occup Med 2006; 30:233-43.

14. Stanley AC, Fernandez NN, Lounsbury KM, Corrow K, Osler T, and Healey C. Pressure-induced cellular senescence: a mechanism linking venous hypertension to venous ulcers. J Surg Res 2005; 124:112-7.

15. Tuchsen F, Krause N, Hannerz H, Burr H, and Kristensen TS. Standing at work and varicose veins. Scand J work Environ Health 2000; 26:414-20. 